Portland State University

PDXScholar

TREC Final Reports

Transportation Research and Education Center

(TREC)

$10-2017$

\title{
Does Compact Development Increase or Reduce Traffic Congestion?
}

\author{
Reid Ewing \\ University of Utah \\ Guang Tian \\ University of Utah \\ Torrey Lyons \\ University of Utah
}

Follow this and additional works at: https://pdxscholar.library.pdx.edu/trec_reports

Part of the Transportation Commons, and the Urban Studies Commons Let us know how access to this document benefits you.

\section{Recommended Citation}

Reid Ewing, Guang Tian, and Torrey Lyons. Does Compact Development Increase or Reduce Traffic Congestion? NITC-RR-1020. Portland, OR: Transportation Research and Education Center (TREC), 2017. https://doi.org/10.15760/trec.187

This Report is brought to you for free and open access. It has been accepted for inclusion in TREC Final Reports by an authorized administrator of PDXScholar. Please contact us if we can make this document more accessible: pdxscholar@pdx.edu. 


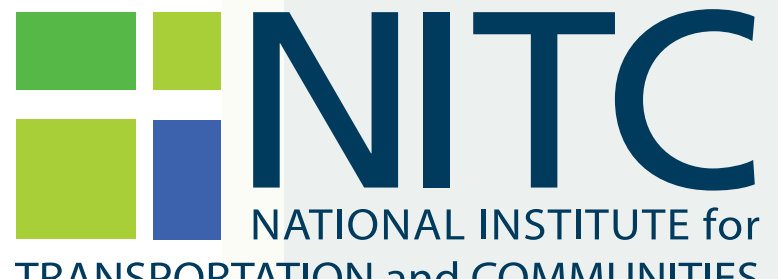

TRANSPORTATION and COMMUNITIES

FINAL REPORT

Does Compact Development Increase or Reduce Traffic Congestion?

NITC-RR-1020 $\quad$ October 2017

NITC is a U.S. Department of Transportation

national university transportation center.

HIII TREC 



\title{
DOES COMPACT DEVELOPMENT INCREASE OR REDUCE TRAFFIC CONGESTION?
}

\author{
Final Report
}

NITC-RR-1020

by

Reid Ewing

Guang Tian

Torrey Lyons

University of Utah

for

National Institute for Transportation and Communities (NITC)

P.O. Box 751

Portland, OR 97207
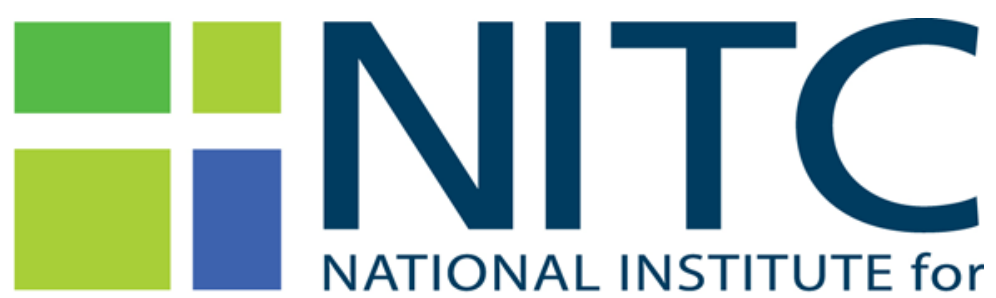

TRANSPORTATION and COMMUNITIES

October 2017 




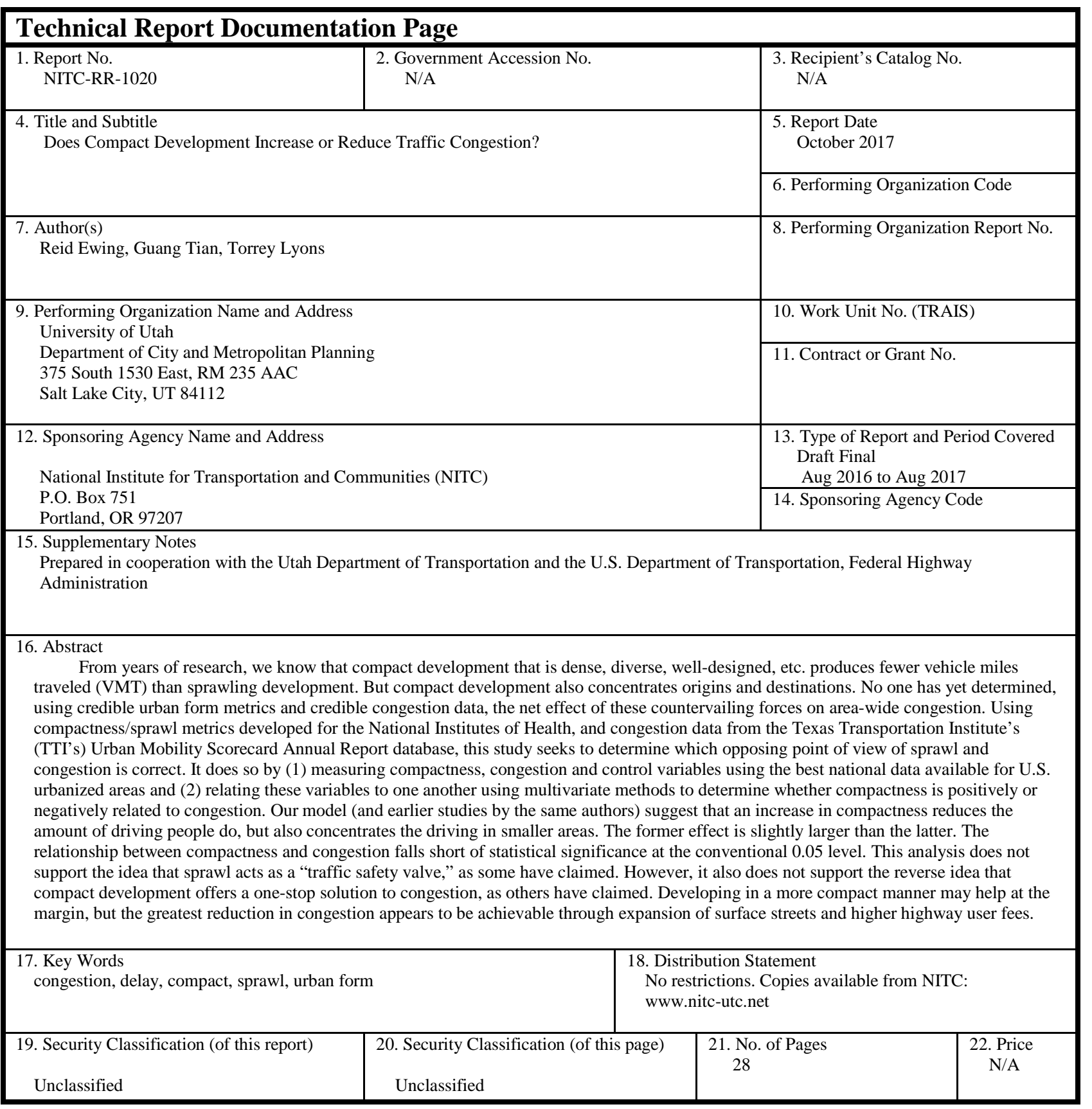




\section{ACKNOWLEDGEMENTS}

We also would like to acknowledge partial support from the National Institute for Transportation and Communities (NITC) under grant number (1020) and the Utah Department of Transportation (16.05.03).

\section{DISCLAIMER}

The contents of this report reflect the views of the authors, who are solely responsible for the facts and the accuracy of the material and information presented herein. This document is disseminated under the sponsorship of the U.S. Department of Transportation University Transportation Centers Program in the interest of information exchange. The U.S. Government assumes no liability for the contents or use thereof. The contents do not necessarily reflect the

official views of the U.S. Government. This report does not constitute a standard, specification, or regulation.

\section{RECOMMENDED CITATION}

Ewing, Reid, Tian, Guang, \& Lyons, Torrey. Does compact development increase or reduce traffic congestion? NITC-RR-1020. Portland, OR: Transportation Research and Education Center (TREC), 2017. 


\section{TABLE OF CONTENTS}

EXECUTIVE SUMMARY …...................................................................................................... 1

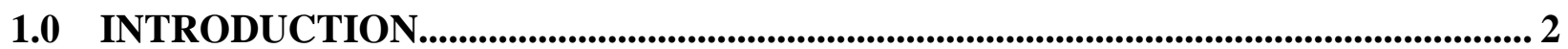

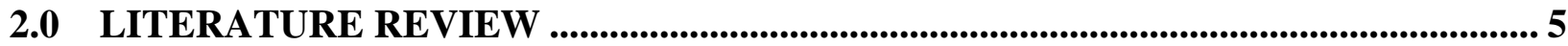

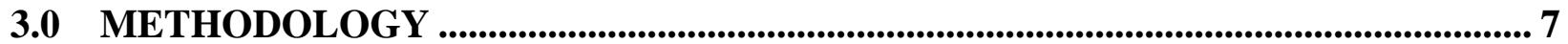

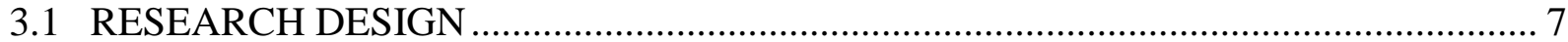

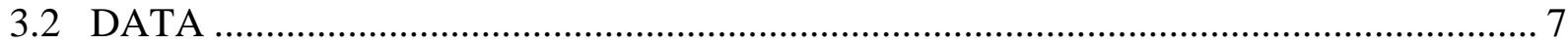

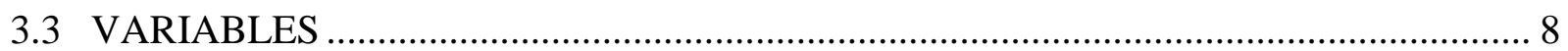

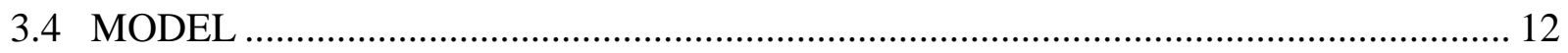

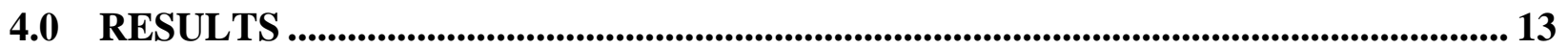

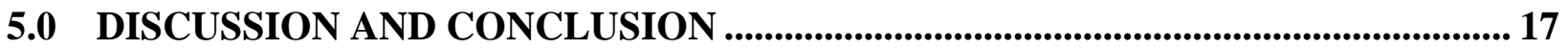

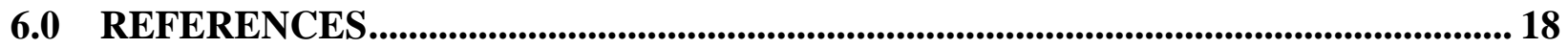

\section{LIST OF TABLES}

Table 3.1: Compactness/sprawl scores for 10 most compact and 10 most sprawling UZAs in

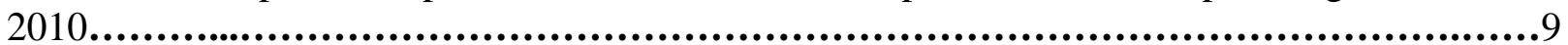

Table 3.2: Variables included in the model..................................................11 Table 4.3: Path coefficient estimates (regression coefficients) and associated statistics for direct effects in the model (see Figure 3.2) ..................................................... Table 4.4: Direct, indirect and total effects of variables on delay per capita in the model (see

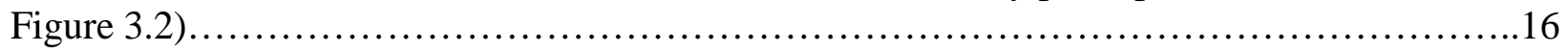

\section{LIST OF FIGURES}

Figure 2.1: Conceptual framework

Figure 3.1: The aerial images of the San Francisco-Oakland urbanized area (a) and the Atlanta urbanized area (b) from Google Earth

Figure 3.2: Casual path diagram explaining delay per capita for urbanized areas (for clarity, some correlational arrows have been omitted). 



\section{EXECUTIVE SUMMARY}

From years of research, we know that compact development that is dense, diverse, welldesigned, etc. produces fewer vehicle miles traveled (VMT) than sprawling development. But compact development also concentrates origins and destinations. No one has yet determined, using credible urban form metrics and credible congestion data, the net effect of these countervailing forces on area-wide congestion. Using compactness/sprawl metrics developed for the National Institutes of Health, and congestion data from the Texas Transportation Institute's (TTI's) Urban Mobility Scorecard Annual Report database, this study seeks to determine which opposing point of view of sprawl and congestion is correct. It does so by (1) measuring compactness, congestion and control variables using the best national data available for U.S. urbanized areas and (2) relating these variables to one another using multivariate methods to determine whether compactness is positively or negatively related to congestion. Our model (and earlier studies by the same authors) suggest that an increase in compactness reduces the amount of driving people do, but also concentrates the driving in smaller areas. The former effect is slightly larger than the latter. The relationship between compactness and congestion falls short of statistical significance at the conventional 0.05 level. This analysis does not support the idea that sprawl acts as a "traffic safety valve," as some have claimed. However, it also does not support the reverse idea that compact development offers a one-stop solution to congestion, as others have claimed. Developing in a more compact manner may help at the margin, but the greatest reduction in congestion appears to be achievable through expansion of surface streets and higher highway user fees. 


\subsection{INTRODUCTION}

In 1958 William Whyte in his book The Exploding Metropolis referred to a new notion in planning, "suburban sprawl," and alerted Americans that their cities were becoming more sprawling. This began the debate over sprawl and its impacts. There is still little agreement on the definition of sprawl or its alternatives: compact development, pedestrian-friendly design, transit-oriented development, and the catch-all term "smart growth." There is also little consensus about how sprawl impacts everything from housing affordability to traffic congestion to air quality. Duany et al. (2000) use cultural, aesthetic and ecological reasons to reject suburban sprawl as human habitat. At the other end of the spectrum, Bruegmann (2006) describes suburban sprawl as a benign manifestation of the American Dream of a big house in the suburbs.

Fifteen years ago, Smart Growth America (SGA) and the U.S. Environmental Protection Agency (EPA) sought to raise the level of the debate over metropolitan sprawl, from purely subjective and qualitative to largely objective and quantitative (Ewing et al., 2002). They sponsored research to operationally define sprawl and study its relationship to quality-of-life outcomes. The resulting indices place sprawl at one end of a continuous scale and compactness at the other. These compactness/sprawl indices have been widely used in health and other research. The indices have been related to traffic fatalities, travel mode choices, physical inactivity, obesity, heart disease, cancer prevalence, air pollution, extreme heat events, residential energy use, social capital, emergency response times, teenage driving, private-vehicle commute distances and times, housing-plus-transportation costs, and economic and social mobility (Ewing and Hamidi, 2015). While most studies have linked sprawl to negative outcomes, there have been exceptions (see, in particular, Holcombe and Williams, 2012).

One area where the relative advantages of sprawl versus compact development has not been convincingly argued is in terms of traffic congestion. Limiting traffic congestion is one of the goals (if not the primary goal) of transportation agencies around the country. The Texas Transportation Institute (TTI) estimates that congestion cost the American commuter and taxpayer \$160 billion in 2014 (TTI, 2015). Referring to congestion as a problem compels action, principally widening roads. Yet, as Litman says (2009, p. 1-6): “Calling congestion a problem implies that it must be fixed, but describing it as a cost recognizes that a certain amount of congestion may be acceptable compared with the costs involved in eliminating it.”

State departments of transportation and metropolitan planning organizations (MPOs) dole out billions annually for specific roadway construction projects to widen existing highways or build new corridors. Although billions of dollars have been spent on added capacity throughout the past few decades, each region in the country has experienced increased congestion over this period. For all but eight of the 101 urbanized areas in the TTI sample, annual delay per commuter more than doubled between 1982 (the first year in the series) and 2014 (the last year in the series). For all but one urbanized area, annual delay per commuter increased by more than 40 percent over this same period. 
For this reason and others, MPOs are increasingly resorting to land use scenario planning and land use strategies (through the local governments that comprise them) to create future growth patterns that are more compact than "trend" or "business as usual." In regional vision, scenario and transportation plans, compact development mainly means developing a hierarchy of compact, mixed-use, walkable and transit-served centers, and using transportation investments to channel growth into these centers. Think Portland, OR. Back in the 1990s, three scenarios were compared for their impacts on quality of life in the region: a "growing out" or sprawl scenario, a "growing up" or infill scenario, and a "neighboring cities" or polycentric scenario. The 2040 recommended alternative, adopted by the Metro Council in 1995, was a combination of scenarios two and three. The 2040 Growth Concept outperformed sprawl in terms of traffic congestion and many other outcome measures.

The Portland model has become the dominant regional planning paradigm in the United States, a paradigm which concentrates development in centers connected by high-quality transit. One of the advantages of this polycentric pattern over sprawl, it is argued, is reduced traffic congestion (Ewing and Bartholomew, 2017).

If the most convincing argument in favor of sprawl is that it acts as a "traffic safety valve," what if, in fact, this were not the case? Using the compactness/sprawl metrics methodology developed by Ewing and Hamidi (2014), and congestion data from TTI's Urban Mobility Scorecard Annual Report database, this study (1) measures compactness, congestion and control variables using the best national data available for U.S. urbanized areas and (2) relates these variables to one another using structural equation models to determine whether compactness is positively or negatively related to area-wide congestion, or possibly unrelated due to the countervailing forces of dispersed origins and destinations with sprawl but also increased VMT with sprawl. 



\subsection{LITERATURE REVIEW}

In 1997, the Journal of the American Planning Association published a pair of pointcounterpoint articles now listed by the American Planning Association as "classics" in the urban planning literature. In the first article, “Are Compact Cities Desirable?” Gordon and Richardson argued in favor of urban sprawl as a benign response to consumer preferences. In the counterpoint article, “Is Los Angeles-Style Sprawl Desirable?” Ewing argued for compact cities as an alternative to sprawl. They disagreed about nearly everything: the characteristics, causes and costs of sprawl, and the cures for any costs associated with sprawl.

Gordon and Richardson said at the time and since that suburban sprawl acts as a "traffic safety valve, more of a solution than a problem." They go on to say: "Suburbanization has been the dominant and successful mechanism for reducing congestion. It has shifted road and highway demand to less congested routes and away from core areas. All of the available recent data from national surveys on self-reported trip lengths and/or durations corroborate this view." They note that most people live and work in the suburbs, and that most commuting is from suburb to suburb. A concept central to their claim is that as activities are spread across a greater area, and more roads are built to accommodate them, the resulting trips will also spread out, in turn, reducing congestion. Ewing took the opposite tack, arguing that sprawl, by definition, means spread out development where every trip is by automobile and many trips are long. He cited increases in average commute times from census to census. Neither article looked directly at congestion levels.

From the theoretical perspective, it is not obvious whose position is strongest. From years of research, we know that compact development that is dense, diverse, well-designed, etc. produces fewer vehicle miles traveled (VMT) than sprawling development. But compact development also concentrates origins and destinations (OD), as shown in Figure 2.1. Since VMT is positively related to congestion, a reduction in VMT with compact development would tend to reduce congestion. And since concentrated OD pairs are positively related to congestion, an increase in concentration with compact development would then increase congestion. No one has yet determined, using credible urban form metrics and credible congestion data, the net effect of these countervailing forces on area-wide congestion. 


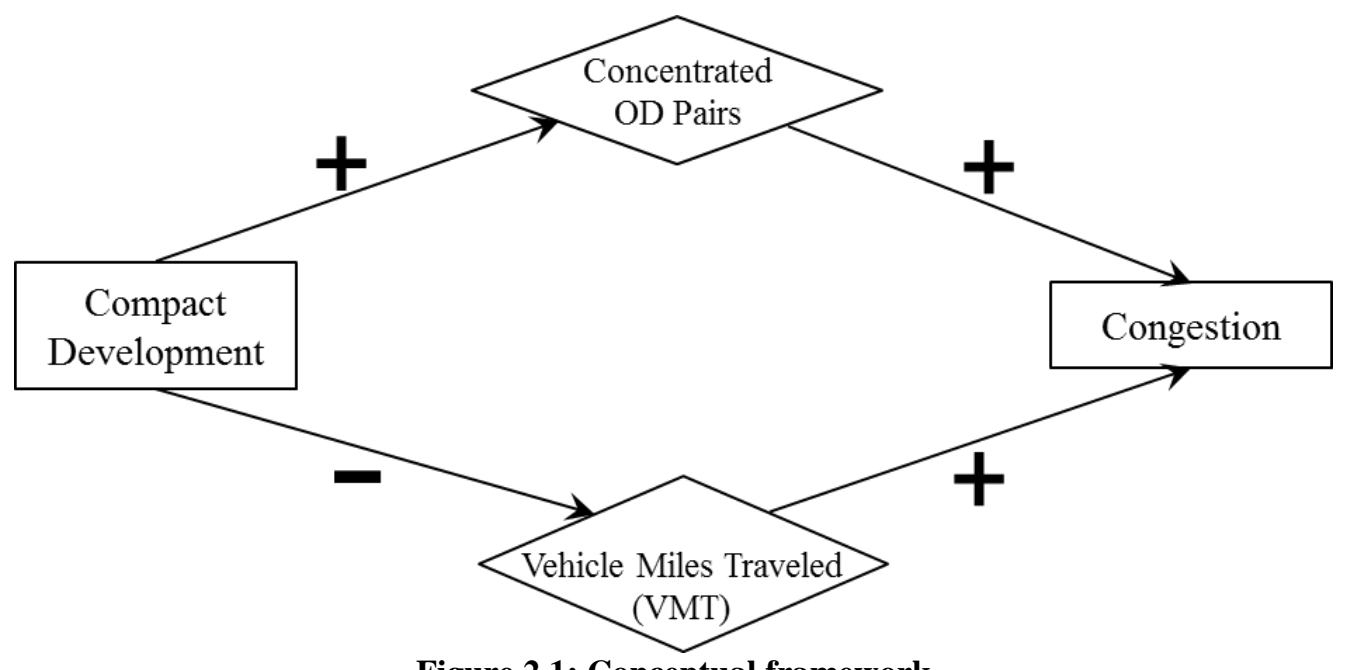

Figure 2.1: Conceptual framework

At the time of the point-counterpoint, sprawl measures had not been developed. Now that they have been developed, we have more direct evidence on the relationship between sprawl and congestion. After controlling for population size and sociodemographic variables, Ewing et al. (2002) found no association between their overall metropolitan sprawl index and either mean journey-to-work time in minutes or annual traffic delay per capita. The individual dimensions of sprawl seem to neutralize each other. While VMT is higher in sprawling areas, so apparently are average travel speeds.

Other researchers have weighed in on this debate as well, with mixed results. Crane and Chatman (2003) looked into the relationship between commute times and employment location. They found that with increased suburbanization of employment (measured by the regional concentration of employment) there was an associated decrease in commute times. In this case, travel times were being used as a proxy for congestion.

In a more recent study, using aggregated commute data from the American Community Survey, Gordon and Lee (2013) also found that job dispersion rather than just density or population dispersion is the critical factor for congestion and travel time. "Given the population size and suburbanization, more decentralized and dispersed employment distribution was associated with shorter average commute time” (Gordon and Lee, 2013, p. 9).

Sarzynski et al. (2006) significantly advanced cross-sectional research on commuting by using more elaborate urban form variables and addressing potential endogeneity and time-lag effects between urban structure and congestion. Their regression analysis with a sample of the 50 largest urban areas provided mixed results. They found that, controlling for prior levels of congestion and changes in an urban area's transport network and relevant demographics, density/contiguity and housing centrality were positively related to subsequent delay per capita, and housing-job proximity was inversely related to subsequent commute time. They concluded that only the last result corresponds to the conventional wisdom that more compact metropolitan land use patterns reduce traffic congestion. 
Using the same sprawl index as Ewing et al. (2002) and a different source of commuting data, Kahn (2006) concluded that sprawling areas have an edge with respect to both travel speeds and overall commuting times. "Relative to workers in compact cities, workers in sprawled cities commute an extra 1.8 miles further each way but their commute is 4.3 minutes shorter. Over the course of a year (400 trips), they save 29 hours. While the workers living in sprawled cities have a longer commute measured in miles, they are commuting at higher speeds...workers in sprawled cities commute at a speed 9.5 miles per hour faster than workers in compact cities” (Kahn, 2006, p. 6).

The above discussion demonstrates a lack of consensus on the impacts of sprawl on congestion, as well as a clear need for more empirical analysis. It also suggests that how we measure sprawl may affect the resulting relationship between sprawl and congestion. Finally, it suggests that the use of proxies for congestion, such as commute times, may lead to different conclusions than the use of congestion measures themselves.

\subsection{METHODOLOGY}

\subsection{RESEARCH DESIGN}

In this study, a cross-sectional study design is used with structural equation modeling (SEM) to estimate the long-run relationships between transportation and land use at a point in time. It is hypothesized that long-run relationships are explained by these models as each urbanized area has had decades to arrive at quasi-equilibrium among land use patterns, road capacity, transit service, VMT and traffic congestion.

SEM is a statistical technique for evaluating complex hypotheses involving multiple, interacting variables. The estimation of SEM models involves solving a set of equations. There is an equation for each "response” or "endogenous" variable in the system. Both response and endogenous variables are affected by others, and may also affect other variables. Variables that are solely predictors of other variables are termed "influences" or "exogenous" variables. They may be correlated with one another but are determined outside the system.

Typically, model selection processes for SEM models focus on observed versus model-implied correlations in the data. The unstandardized correlations or co-variances are the raw material for the analyses. Models are automatically compared to a "saturated" model (one that allows all variables to inter-correlate), and this comparison allows the analysis to discover missing pathways and, thereby, reject inconsistent models.

\subsection{DATA}

In a study parallel to this one, Ewing et al. (2014) related VMT per capita for urbanized areas to population density, highway capacity, transit service, average fuel price and other covariates. In this paper, we use the same dataset to explore the relationship between compactness/sprawl and 
congestion. Data for the original article were gathered from several primary sources, including Federal Highway Administration (FHWA) Highway Statistics, the U.S. Census American Community Survey, National Transit Database, etc. Readers are referred to that article for a description of the variables in the original dataset.

This study differs from the original study in two primary respects. First, rather than using population density as a descriptor of urban form, we use a more complete compactness/sprawl index. Second, rather than focusing on the outcome variable VMT per capita, we focus on a measure of congestion.

Consistent with Hamidi and Ewing (2014), we limited our sample to larger urbanized areas with populations of 200,000 or more. The rationale for limiting our sample is that small urban areas are different qualitatively than large urban areas. We wanted a more homogenous sample. In small areas, land uses are necessarily reasonably proximate to each other, and according to TTI's Scorecard Annual Report, congestion levels are consistently low. Hence reasonable accessibility, which defines compactness, is guaranteed. It is spurious to compare congestion in a large area like Los Angeles (population 12.6 million, where trips are long and congestion is intolerable) to congestion in a small area like Porterville, CA (population 79 thousand, where trips are necessarily short and congestion is nonexistent). Our final sample consists of 157 urbanized areas.

\subsection{VARIABLES}

Our definition of sprawl is borrowed directly from the literature. Sprawl is any development pattern characterized by poor accessibility and automobile dependence. As in Ewing et al. (2002), Ewing and Hamidi (2014) and other studies previously referenced, sprawl is operationally defined as low-density, single-use, uncentered or poorly connected development.

Using the metrics of Ewing and Hamidi , the 10 most compact areas and 10 most sprawling urbanized areas are shown in Table 3.1. The aerial images of the San Francisco-Oakland urbanized area and the Atlanta urbanized area are shown in Figure 3.1. One can see how different they are in terms of sprawl.

Both the individual factors and overall index have been validated against transportation outcome measures (Ewing et al., 2003; Hamidi et al., 2015; Hamidi and Ewing, 2014; Ewing and Hamidi, 2014). The overall index has also been widely used in the literature (Congdon, 2016; Ewing et al., 2014; Ewing et al., 2016a; Ewing et al., 2016b; Hamidi and Ewing, 2015; Nelson et al., 2014; Nelson et al., 2015a; Nelson et al., 2015b; Lee, 2015; Sanderford et al., 2015; Sanderford et al., 2016). 
Table 3.1: Compactness/sprawl scores for 10 most compact and 10 most sprawling UZAs in 2010

\begin{tabular}{l|l|c|c|c|c|c}
\hline Rank & $\begin{array}{c}\text { compactness } \\
\text { index }\end{array}$ & $\begin{array}{c}\text { density } \\
\text { factor }\end{array}$ & $\begin{array}{c}\text { mix } \\
\text { factor }\end{array}$ & $\begin{array}{c}\text { centering } \\
\text { factor }\end{array}$ & $\begin{array}{c}\text { street } \\
\text { factor }\end{array}$ \\
\hline
\end{tabular}

\section{Ten most compact urbanized areas}

\begin{tabular}{|c|c|c|c|c|c|c|}
\hline 1 & San Francisco-Oakland, CA & 175.50 & 190.14 & 88.90 & 169.16 & 148.36 \\
\hline 2 & Reading, PA & 162.19 & 120.74 & 128.44 & 126.47 & 138.92 \\
\hline 3 & Eugene, OR & 155.08 & 118.34 & 128.22 & 123.68 & 127.25 \\
\hline 4 & Madison, WI & 154.73 & 118.70 & 88.50 & 186.95 & 111.97 \\
\hline 5 & Salem, OR & 153.88 & 123.04 & 135.33 & 112.19 & 123.12 \\
\hline 6 & Lexington-Fayette, KY & 152.04 & 134.48 & 123.02 & 124.22 & 112.03 \\
\hline 7 & Huntington, WV-KY-OH & 146.87 & 83.29 & 129.11 & 148.69 & 126.96 \\
\hline 8 & $\begin{array}{l}\text { New York-Newark, NY-NJ- } \\
\text { CT }\end{array}$ & 146.62 & 186.88 & 75.10 & 185.54 & 124.87 \\
\hline 9 & York, PA & 146.17 & 98.46 & 138.95 & 126.74 & 113.29 \\
\hline 10 & Allentown, PA-NJ & 145.91 & 108.68 & 134.48 & 105.34 & 149.70 \\
\hline
\end{tabular}

Ten most sprawling urbanized areas

\begin{tabular}{l|l|r|r|r|r|r}
\hline 148 & Nashville-Davidson, TN & 66.05 & 94.10 & 64.31 & 97.93 & 79.97 \\
\hline 149 & Cleveland, OH & 64.29 & 99.21 & 88.55 & 95.75 & 64.26 \\
\hline 150 & Lancaster-Palmdale, CA & 63.88 & 98.34 & 97.30 & 54.81 & 61.05 \\
\hline 151 & Winston-Salem, NC & 63.27 & 70.82 & 89.69 & 89.15 & 61.51 \\
\hline 152 & Fayetteville, NC & 62.90 & 80.58 & 89.21 & 67.29 & 69.36 \\
\hline 153 & Chattanooga, TN-GA & 61.63 & 70.13 & 67.38 & 100.48 & 71.59 \\
\hline 154 & Atlanta, GA & 58.34 & 87.47 & 113.62 & 104.91 & 49.05 \\
\hline 155 & Baton Rouge, LA & 57.67 & 74.57 & 107.36 & 71.05 & 57.73 \\
\hline 156 & Jackson, MS & 55.90 & 63.24 & 94.84 & 104.76 & 36.48 \\
\hline 157 & Shreveport, LA & 45.80 & 66.36 & 71.04 & 68.36 & 66.43 \\
\hline
\end{tabular}




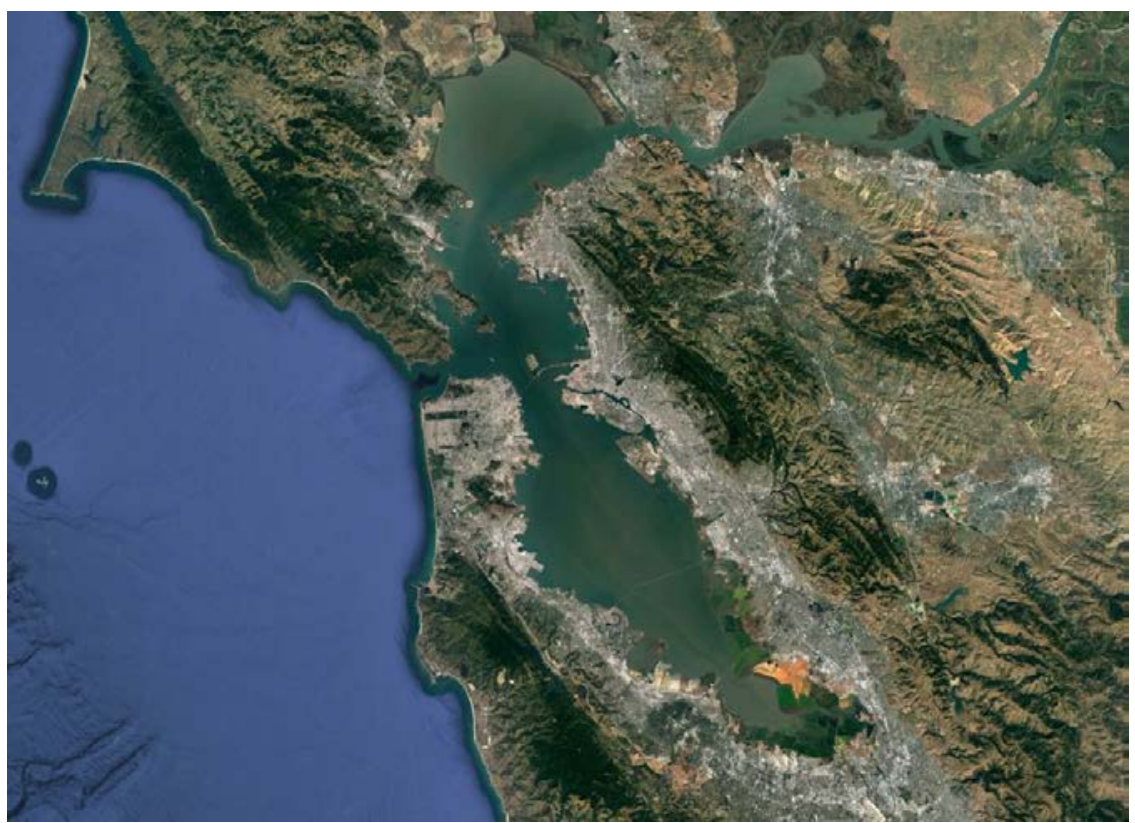

(a) San Francisco-Oakland urbanized area

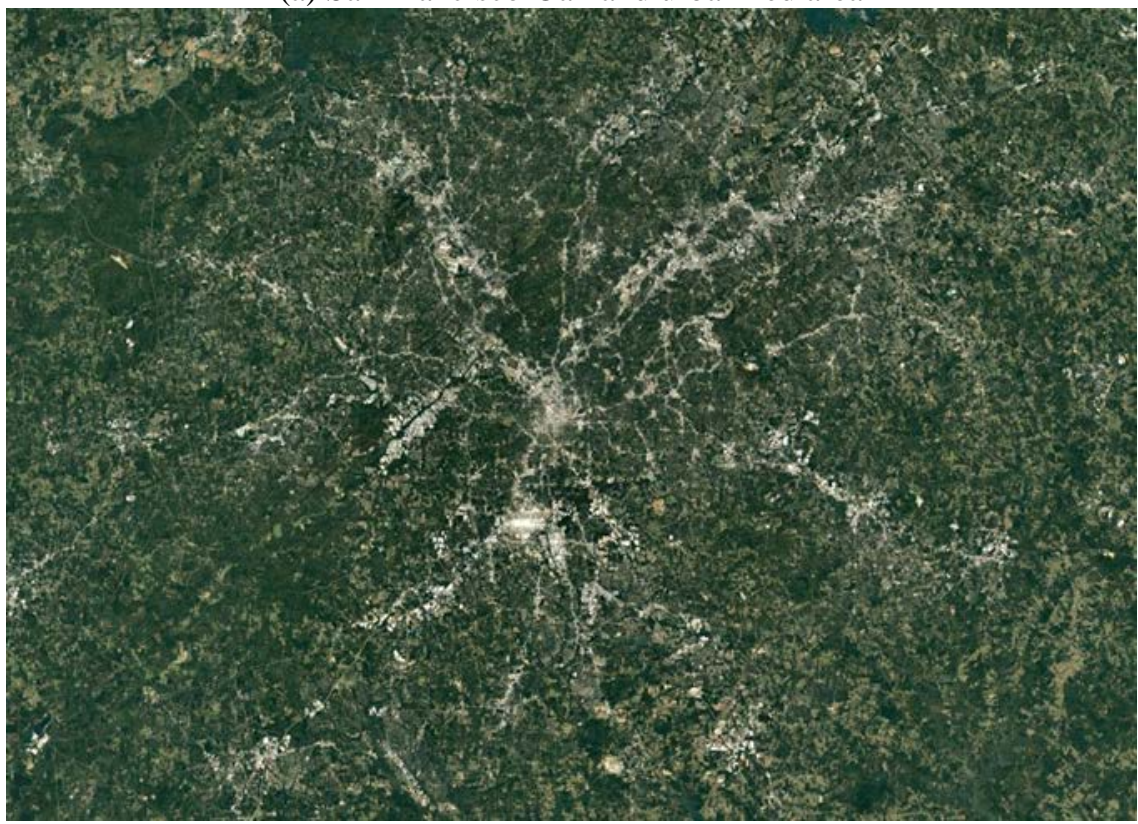

(b) Atlanta urbanized area

Figure 3.1: The aerial images of the San Francisco-Oakland urbanized area and the Atlanta urbanized area from Google Earth

Congestion data come from the TTI's Urban Mobility Scorecard Annual Report database. TTI congestion data are derived from INRIX traffic speed data for 471 U.S. urbanized areas in 2014 (TTI, 2015). Speeds collected by INRIX every 15 minutes from a variety of sources every day of the year on almost every major road were used. The data for all 96 15-minute periods of the day makes it possible to track congestion problems for the midday, overnight and weekend time periods. TTI provides different measures of congestion, such as annual hours of delay and the travel time index. We chose annual hours of delay per capita to measure congestion, instead of the travel time index. We contacted the TTI authors and they recommended annual hours of 
delay as a broader measure of congestion since it covers 24 hours, instead of just peak hours like the travel time index.

The variables in our model are defined in Table 3.2. The variables fall into three general classes:

- Our outcome variable, annual delay per capita.

- Exogenous explanatory variables. The exogenous variables, population and per capita income, are determined by regional competitiveness. The real fuel price is determined by federal and state tax policies and regional location relative to ports of entry and refining capacity.

- Endogenous explanatory variables. The endogenous variables are a function of exogenous variables and are, in addition, related to one another. They depend on real estate market forces and regional and policy decisions: whether to increase highway and local street capacity, whether to increase transit revenue service, whether to zone for higher densities, and whether to aim to reduce VMT. The compactness index is an endogenous variable which affects annual delay per capita both directly and indirectly.

In the analysis, all variables were transformed by taking natural logarithms. The use of logarithms has two advantages. First, it makes relationships among variables more nearly linear and reduces the influence of outliers (such as New York and Los Angeles). Second, it allows us to interpret parameter estimates as elasticities, which summarize relationships in an understandable and transferable form. An elasticity is a percentage change in one variable associated with a 1 percent change in another variable (a ratio when these changes are infinitely small). Elasticities are dimensionless (unit-free) measures of the associations between pairs of variables, and are the most widely used measures of effect size in economic and planning research.

Table 3.2: Variables included in the model

\begin{tabular}{|c|c|c|c|c|}
\hline Variable & Definition & Source & Mean & Sta. Dev. \\
\hline \multicolumn{5}{|c|}{ Outcome variable } \\
\hline delay & Natural log of annual delay per capita & TTI congestion data & 3.25 & 0.38 \\
\hline \multicolumn{5}{|c|}{ Exogenous variable } \\
\hline pop & Natural log of population (in thousands) & U.S. Census & 6.40 & 0.96 \\
\hline inc & $\begin{array}{l}\text { Natural log of income per capita (in } \\
\text { thousands) }\end{array}$ & $\begin{array}{l}\text { American Community } \\
\text { Survey }\end{array}$ & 3.27 & 0.19 \\
\hline fuel & Natural log of average metropolitan fuel price & Oil Price Information Service & 1.02 & 0.06 \\
\hline \multicolumn{5}{|c|}{ Endogenous variable } \\
\hline flm & $\begin{array}{l}\text { Natural log of freeway lane miles per } 1000 \\
\text { population }\end{array}$ & FHWA Highway Statistics & -0.49 & 0.42 \\
\hline olm & $\begin{array}{l}\text { Natural log of other lane miles per 1,000 } \\
\text { population }\end{array}$ & $\begin{array}{l}\text { FHWA Highway Statistics } \\
\text { NAVTEQ }\end{array}$ & 0.85 & 0.28 \\
\hline rtden & $\begin{array}{l}\text { Natural log of transit route density per square } \\
\text { mile }\end{array}$ & National Transit Database & 0.60 & 0.75 \\
\hline tfreq & Natural log of transit service frequency & National Transit Database & 8.68 & .55 \\
\hline tpm & $\begin{array}{l}\text { Natural log of annual transit passenger miles } \\
\text { per capita }\end{array}$ & National Transit Database & 4.00 & 1.15 \\
\hline compact & Natural log of the compactness index & $\begin{array}{l}\text { Many sources - see reference } \\
\text { (Ewing and Hamidi, 2014) }\end{array}$ & 4.57 & 0.25 \\
\hline
\end{tabular}




\subsection{MODEL}

The SEM was estimated with the software package Amos and maximum likelihood procedures. The path diagram in Figure 3.2 is copied directly from Amos. Causal pathways are represented by unidirectional straight arrows. Correlations are represented by curved bidirectional arrows (to simplify the already complex causal diagrams, some correlations are omitted). By convention, circles represent error terms in the model, of which there is one for each endogenous (response) variable.

Most of the causal paths shown in the path diagram are statistically significant (long-term probability of observing zero is less than 5 percent). The exceptions are a few paths that are theoretically significant, though not statistically significant (i.e., the mechanism is hypothesized to operate based on substantive knowledge, but its observed effect is variable).

The main goodness-of-fit measure used to select models was the chi-square statistic. Probability statements about an SEM model are reversed from those associated with null hypotheses.

Probability values ( $p$-value) used in statistics are measures of the degree to which the data are unexpected, given the hypothesis being tested. In null hypothesis testing, a finding of a $p$-value < 0.05 indicates that we can reject the null hypothesis because the relationships are very unlikely to come from a random association. In SEM, we seek a model with a small chi-square and large $p$ value (>0.05). A chi-square test assesses how well the model fits the data. A high chi-square value leads one to reject the hypothesized model (Hox and Bechger, 1998). 


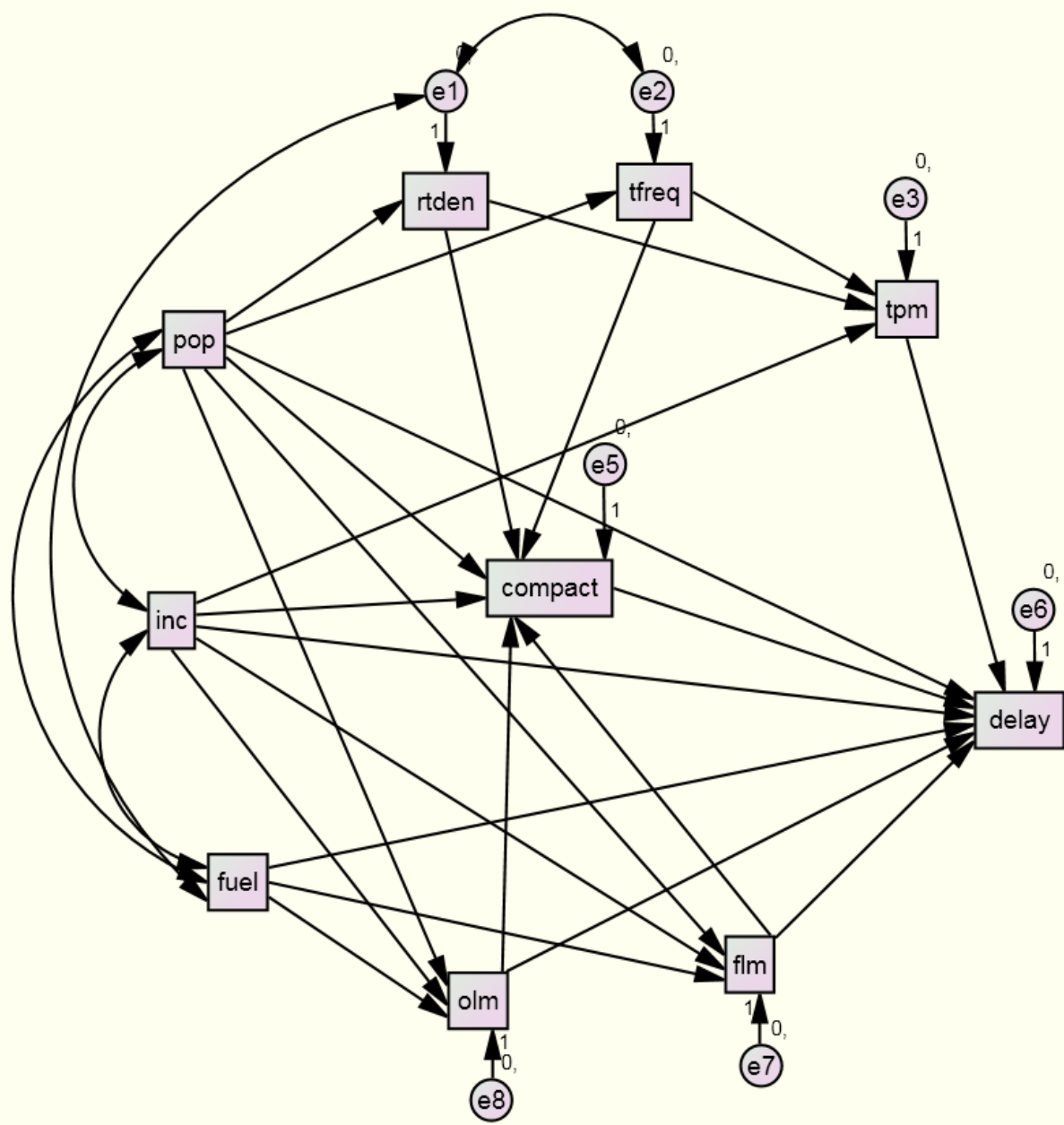

Figure 3.2: Casual path diagram explaining delay per capita for urbanized areas (for clarity, some correlational arrows have been omitted).

\subsection{RESULTS}

The delay model in Figure 3 has a chi-square of 12.1 with 12 model degrees of freedom, a pvalue of 0.44, a Comparative Fit Index (CFI) of 1.0, and a root mean square error of approximation (RMSEA) of 0.008. The low chi-square relative to model degrees of freedom and a high $(>0.05)$ p-value are indicators of good model fit to the data. Furthermore, the CFI greater than the preferred minimum value of 0.95 and RMSEA smaller than the preferred maximum value of 0.06 also indicate a good model fit to the data (Schreiber et al., 2006). With the exception of causal pathways of theoretical interest, the final model includes only causal pathways whose path coefficients (regression coefficients) are statistically significant.

The path coefficients in Table 4.1 give the predicted effects of individual variables and associated null probabilities. These are the direct effects of one variable on another. They do not account for the indirect effects through other endogenous variables. 
Most of the relationships in Table 4.1 align with expectations. Larger urbanized areas, measured in terms of population, provide more transit service and fewer lane miles of highway per capita. They are generally less auto-centric than smaller areas. Larger areas, measured in terms of population, have more delay per capita since they have more people competing for road space and longer peak periods.

Wealthier areas have more highway capacity per capita, both in freeways and other roads. Despite this, they have more congestion. The reason, as the literature shows, is a strong relationship between income on the one hand, and automobile ownership and use on the other. An earlier study found that the elasticity of VMT per capita with respect of income per capita is 0.351 (Ewing et al., 2017).

Areas with higher fuel prices have less highway capacity per capita, and are generally less autodependent. An earlier study found that the elasticity of VMT per capita with respect of average fuel price is -0.692 (Ewing et al., 2017). That is the strongest relationship between VMT and any variable tested. Because of this relationship, and the nonlinear relationship between traffic volume, capacity and congestion, average fuel price is strongly and negatively related to delay per capita.

Areas with higher transit route density and transit service frequency have higher transit passenger miles per capita. Areas with more transit service are also more compact. The relationship between transit service and compactness is doubtless bidirectional, but the conventional wisdom (from Homer Hoyt until the present) says that "urban form is largely a product of the dominant transportation system in place during a region's prevailing period of growth.”

Areas with more lane miles of roadway capacity (other than freeways) are significantly less compact than those with less capacity. Certainly, in the case of arterials, this could be due to highway-induced development. However, the added capacity of surface streets appears to overwhelm that added VMT associated with induced traffic (Ewing et al., 2017), and the net effect is reduced congestion in areas with extensive street networks.

There are a few direct relationships that are unexpected and harder to explain. Areas with higher per capita incomes have more transit passenger miles per capita. Looking at individual data points, this may simply reflect the fact that larger urbanized areas tend to have higher incomes and better transit service, a confounding effect that is apparently not controlled in our SEM.

Also unexpected is the fact that areas with more freeway capacity per 1,000 population have as much delay per capita as those with less freeway capacity, though no more. The direct relationship between freeway capacity and delay is not significant. This result may be spurious or it could reflect freeway-induced travel demand. Freeways often have extreme congestion during rush hours, more extreme than do surface streets. When you think of large urbanized areas with extensive freeway systems, you also think of rush-hour congestion. 
The third unexpected result is that freeway capacity in lane miles per 1,000 population has no relationship to our compactness index. Due to highway-induced development, we would expect a strong negative relationship between the two. This one finding is the hardest to explain.

Finally, and most importantly, areas that are more compact are not characterized by more annual delay per capita, if anything less. The relationship between compactness and congestion falls short of statistical significance at the conventional level.

Table 4.1: Path coefficient estimates (regression coefficients) and associated statistics for direct effects in the model (see Figure 3.2)

\begin{tabular}{|c|c|c|c|c|c|c|}
\hline & & & Estimate & S.E. & C.R. & p-value \\
\hline rtden & $<---$ & pop & 0.237 & 0.06 & 3.929 & $<0.001$ \\
\hline tfreq & $<---$ & pop & 0.308 & 0.038 & 8.026 & $<0.001$ \\
\hline flm & $<---$ & pop & -0.051 & 0.035 & -1.435 & 0.151 \\
\hline flm & $<---$ & fuel & -2.682 & 0.57 & -4.706 & $<0.001$ \\
\hline flm & $<---$ & inc & 0.467 & 0.183 & 2.547 & 0.011 \\
\hline olm & $<---$ & pop & -0.124 & 0.019 & -6.464 & $<0.001$ \\
\hline olm & $<---$ & inc & 0.299 & 0.096 & 3.113 & 0.002 \\
\hline olm & $<---$ & fuel & -2.463 & 0.314 & -7.85 & $<0.001$ \\
\hline tpm & $<---$ & inc & 1.357 & 0.252 & 5.377 & $<0.001$ \\
\hline tpm & $<---$ & rtden & 0.937 & 0.061 & 15.314 & $<0.001$ \\
\hline tpm & $<---$ & tfreq & 0.965 & 0.086 & 11.223 & $<0.001$ \\
\hline compact & $<---$ & pop & -0.107 & 0.022 & -4.864 & $<0.001$ \\
\hline compact & $<---$ & inc & 0.241 & 0.091 & 2.657 & 0.008 \\
\hline compact & $<---$ & flm & -0.031 & 0.039 & -0.781 & 0.435 \\
\hline compact & $<---$ & olm & -0.264 & 0.073 & -3.625 & $<0.001$ \\
\hline compact & $<---$ & rtden & 0.122 & 0.025 & 4.79 & $<0.001$ \\
\hline compact & $<---$ & tfreq & 0.094 & 0.035 & 2.701 & 0.007 \\
\hline delay & $<---$ & pop & 0.181 & 0.031 & 5.791 & $<0.001$ \\
\hline delay & $<---$ & inc & 0.474 & 0.139 & 3.415 & $<0.001$ \\
\hline delay & $<---$ & fuel & -2.165 & 0.511 & -4.237 & $<0.001$ \\
\hline delay & $<---$ & flm & 0.081 & 0.058 & 1.404 & 0.16 \\
\hline delay & $<---$ & olm & -0.24 & 0.114 & -2.113 & 0.035 \\
\hline delay & $<---$ & tpm & 0.022 & 0.026 & 0.845 & 0.398 \\
\hline delay & $<---$ & compact & -0.119 & 0.106 & -1.128 & 0.259 \\
\hline
\end{tabular}

Perhaps of greater interest than the direct effects of variables on one another are the total effects of different variables on delay per capita, accounting for both direct and indirect pathways in Table 4.2. Population is a driver of congestion, largely through its direct effect.

Per capita income also is a driver of congestion. Income has a direct effect on delay per capita, mainly through its impact on VMT. 
Added lane miles of roadways (other than freeways) per 1,000 population mitigates congestion. This is the result of a strong direct effect, offset only slightly by an indirect effect of roadway capacity on highway capacity.

Of greatest interest to us is the relationship between compactness and delay per capita. Areas that are more compact and less sprawling generate less VMT per capita (Ewing et al., 2017). This makes sense. Automobile trips are shorter, and alternatives to the automobile (particularly walking, which is not operationalized in our model) are more frequently used (Ewing et al., 2015; Tian et al., 2015). On the other hand, areas that are more compact and less sprawling concentrate trip ends. The former effect is greater than the latter, but the two effects largely cancel each other out. This analysis does not support the idea that sprawl acts as a "traffic safety valve.” At the same time, it provides only weak support for the reverse idea that compact development offers a solution to congestion.

Table 4.2: Direct, indirect and total effects of variables on delay per capita in the model (see Figure 3.2)

\begin{tabular}{l|r|r|r}
\hline & Direct Effect & Indirect Effect & \multicolumn{1}{c}{ Total Effect } \\
\hline pop & 0.181 & 0.039 & 0.22 \\
\hline fuel & -2.165 & 0.287 & -1.878 \\
\hline inc & 0.474 & -0.022 & 0.452 \\
\hline flm & $0.081^{*}$ & 0.004 & 0.085 \\
\hline olm & -0.24 & 0.032 & -0.209 \\
\hline tfreq & 0 & 0.01 & 0.01 \\
\hline rtden & 0 & 0.006 & 0.006 \\
\hline tpm & $0.022 *$ & 0 & 0.022 \\
\hline compact & $-0.119 *$ & 0 & -0.119 \\
\hline
\end{tabular}

* Indicates effects that include a non-significant direct link. 


\subsection{DISCUSSION AND CONCLUSION}

This paper sought to determine whether claims that sprawl can function as a "traffic safety valve” are true or not. The most widely used compactness/sprawl index has, when both direct and indirect effects are considered, essentially no relationship to a widely accepted and cited measure of congestion. It is not clear from this analysis whether travel times, which after all are what really matter, are shorter or longer with sprawl, since travel distances are greater in sprawling development patterns. Common sense suggests that since origins and destinations are closer together in a compact development pattern, travel times may be shorter. But this represents a topic for further study.

The use of cross-sectional data generally limits the interpretation of the results to associations rather than causal relationships. Studies require association, temporal precedence and isolation in order to make causal statements of interpretation. With structural equation modeling, causal statements can be made based on the results of the models in combination with an established theoretical basis for the causal interpretation. These causal interpretations can only be made when the data square with existing theory. Even then, these causal statements are made with caution because of the possibility of the model being over-fitted, leaving room for specification errors.

An additional limitation of this study stems from our use of aggregate data, where we cannot make inferences from higher to lower levels of analysis without committing an ecological fallacy. Thus, our results are useful at the macro level, but are unsuitable for making inferences at the individual level.

These findings are important not only for bringing planning academia closer to resolving the debate over this particular impact of sprawl, but also for policy planning. As was mentioned above, reducing congestion is the primary objective of transportation agencies. Congestion costs Americans billions of dollars in lost productivity, and policy should reflect the best ways to avoid such inefficiency. Developing in a more compact manner may help at the margin, but the greatest reduction in congestion appears to be achievable through expansion of surface streets and higher highway user fees. While this is counterintuitive, expanding freeways appears to have the exact opposite effect of what is intended, increasing VMT and hence congestion indirectly, without (in this cross-sectional study) relieving congestion directly. Freeway-induced traffic appears to undermine all the good intentions of freeway building. And ultimately, given the strong negative relationship between average fuel price and delay per capita, the U.S. may have to consider higher fuel taxes or congestion pricing to deal with the pervasive increases in congestion documented by TTI in the Urban Mobility Scorecard Annual Report database. 


\subsection{REFERENCES}

Bruegmann, R. (2006). Sprawl: A compact history. Chicago: University of Chicago press.

Congdon, P. (2016). Explaining variations in obesity and inactivity between US metropolitan areas. GeoJournal, 81(2), 211-229.

Crane, R., \& Chatman, D. G. (2003). Traffic and Sprawl: Evidence from US Commuting from 1985-1997 (Vol. 6). University of Southern California.

Duany, A., Plater-Zyberk, E., \& Speck, J. (2001). Suburban nation: The rise of sprawl and the decline of the American dream. Macmillan.

Ewing, R. (1997). Is Los Angeles-style sprawl desirable? Journal of the American Planning Association, 63 (1): 107-126.

Ewing, R. and Bartholomew, K. (2017). Best practices in metropolitan transportation planning. Routledge, New York, under contract.

Ewing, R. and Hamidi, S. (2014). Measuring urban sprawl and validating sprawl measures. National Institutes of Health and Smart Growth America, Washington, D.C., 2014.

Ewing, R., \& Hamidi, S. (2015). Compactness versus sprawl: A review of recent evidence from the United States. Journal of Planning Literature, 30(4), 413-432.

Ewing, R., Hamidi, S., Gallivan, F., Nelson, A. C., \& Grace, J. B. (2014). Structural equation models of VMT growth in US urbanised areas. Urban Studies, 51(14), 3079-3096.

Ewing, R., Hamidi, S., \& Grace, J. B. (2016a). Urban sprawl as a risk factor in motor vehicle crashes. Urban Studies, 53(2), 247-266.

Ewing, R., Hamidi, S., Grace, J. B., \& Wei, Y. D. (2016b). Does urban sprawl hold down upward mobility? Landscape and Urban Planning, 148, 80-88.

Ewing, R., Hamidi, S., Tian, G., Proffitt, D., Tonin, S., \& Fregolent, L. (2017). Testing Newman and Kenworthy's theory of density and automobile dependence. Journal of Planning Education and Research, 0739456X16688767.

Ewing, R., Meakins, G., Hamidi, S., \& Nelson, A. C. (2014). Relationship between urban sprawl and physical activity, obesity, and morbidity-Update and refinement. Health \& Place, 26, 118126. 
Ewing, R., Pendall, R., \& Chen, D. (2002). Measuring sprawl and its impact. Washington D.C.: Smart Growth America.

Ewing, R., Pendall, R., \& Chen, D. (2003). Measuring sprawl and its transportation impacts. Transportation Research Record: Journal of the Transportation Research Board ,1831 (1): 175-183.

Ewing, R., Schieber, R. A., \& Zegeer, C. V. (2003). Urban sprawl as a risk factor in motor vehicle occupant and pedestrian fatalities. American Journal of Public Health, 93(9), 1541-1545.

Ewing, R., Schmid, T., Killingsworth, R., Zlot, A., \& Raudenbush, S. (2003). Relationship between urban sprawl and physical activity, obesity, and morbidity. American journal of health promotion, 18(1), 47-57.

Ewing, R., Tian, G., Goates, J. P., Zhang, M., Greenwald, M. J., Joyce, A., ... \& Greene, W. (2015). Varying influences of the built environment on household travel in 15 diverse regions of the United States. Urban Studies, 52(13), 2330-2348.

Gordon, P., \& Lee, B. (2013). Trends in Commuting and Non-Commuting Travel in US Metropolitan Areas, Chapter 4: Spatial Structure and Travel in the International Handbook on Transport and Development, Hickman, R., et al (eds) UK: Edward Elgar.

Gordon, P., \& Richardson, H. (1997). Are Compact Cities a Desirable Planning Goal? Journal of the American Planning Association, 63: 95-106.

Hamidi, S., Ewing, R., Preuss, I., \& Dodds, A. (2015). Measuring sprawl and its impacts: An update. Journal of Planning Education and Research, 35(1), 35-50.

Hamidi, S., \& Ewing, R. (2014). A longitudinal study of changes in urban sprawl between 2000 and 2010 in the United States. Landscape and Urban Planning, 128, 72-82.

Hamidi, S., \& Ewing, R. (2015). Is Sprawl Affordable for Americans? Exploring the Association between Sprawl and Housing + Transportation Affordability. Transportation Research Record: Journal of the Transportation Research Board, (2500), 75-79.

Holcombe, R. G., \& Williams, D. W. (2012). Urban Sprawl and Transportation Externalities. The Review of Regional Studies, 40 (3): 257-272.

Hox, J. J., \& Bechger, T. M. (1998). An introduction to structural equation modelling. Family Science Review, 11, 354-373.

Kahn, M.E. (2007). The Quality of Life in Sprawled versus Compact Cities. In Transport, Urban Form and Economic Growth, OECD Publishing.

Lee, S. W. (2015). The role of urban spatial structure in reducing VMT and GHG emissions. Doctoral dissertation, University of Illinois at Urbana-Champaign. 
Litman, T. (2009). Transportation cost and benefit analysis. Victoria Transport Policy Institute, 31.

Nelson, A. C., Eskic, D., Ganning, J. P., Hamidi, S., Petheram, S. J., Liu, J. H., \& Ewing, R. (2015a). Retail Rent with Respect to Distance from Light Rail Transit Stations in Dallas and Denver. Urban Studies and Planning Faculty Publications and Presentations. Paper 127. http://pdxscholar.library.pdx.edu/usp_fac/127

Nelson, A. C., Eskic, D., Ganning, J. P., Hamidi, S., Petheram, S. J., Liu, J. H., \& Ewing, R. (2015b). Office rent premiums with respect to distance from light rail transit stations in Dallas and Denver. Urban Studies and Planning Faculty Publications and Presentations. Paper 128. http://pdxscholar.library.pdx.edu/usp_fac/128

Nelson, A. C., Petheram, S., Ewing, R., Stoker, P., \& Hamidi, S. (2014). 20 Compact development as a factor in income resilience among shrinking counties in the United States. Shrinking Cities: A Global Perspective, 71, 301.

Sanderford, A. R., McCoy, A. P., Zhao, D., \& Koebel, C. T. (2016). Inventing the House: CaseSpecific Studies on Housing Innovation. Momentum Press.

Sanderford, A. R., Keefe, M. J., Koebel, C. T., \& McCoy, A. P. (2015). Factors Influencing US Homebuilders' Adoption of Green Homebuilding Products. Journal of Sustainable Real Estate, 7(1), 60-82.

Sarzynski, A., Wolman, H. L., Galster, G., \& Hanson, R. (2006). Testing the conventional wisdom about land use and traffic congestion: The more we sprawl, the less we move? Urban Studies, 43(3), 601-626.

Schreiber, J. B., Nora, A., Stage, F. K., Barlow, E. A., \& King, J. (2006). Reporting structural equation modeling and confirmatory factor analysis results: A review. The Journal of educational research, 99(6), 323-338.

Texas A\&M Transportation Institute and INRIX (TTI), 2015 Urban Mobility Scorecard. http://d2dtl5nnlpfr0r.cloudfront.net/tti.tamu.edu/documents/mobility-scorecard-2015-wappx.pdf.

Tian, G., Ewing, R., White, A., Hamidi, S., Walters, J., Goates, J. P., \& Joyce, A. (2015). Traffic generated by mixed-use developments: Thirteen-region study using consistent measures of the built environment. Transportation Research Record: Journal of the Transportation Research Board, (2500), 116-124. 
Transportation Research and Education Center

Portland State University

1900 S.W. Fourth Ave., Suite 175

Portland, OR 97201 